\title{
The Influence of Additive-Free Process on the Microstructure of Very Narrow Cu Wires in the Lower Region of a Trench
}

\author{
Yiqing $\mathrm{Ke}^{1}$, Takakshi Namekawa ${ }^{2}$, Kunihiro Tamahashi ${ }^{2}$ and Jin Onuki ${ }^{2}$ \\ ${ }^{1}$ Graduate School of Science and Engineering, Ibaraki University, Hitachi 316-8511, Japan \\ ${ }^{2}$ Department of Materials Science and Engineering, Ibaraki University, Hitachi 316-8511, Japan
}

\begin{abstract}
Microstructure distribution along the trench depth direction of nano-scale copper interconnects was studied as a function of plating material purity. It was shown that, after annealing in the lower region of the trench, the $\mathrm{Cu}$ wire fabricated by the additive-free process has $13 \%$ larger grains and $80 \%$ lower ratio of small grains (less than $45 \mathrm{~nm}$ ) than the wire fabricated by the high-purity process, and $25 \%$ larger grains and $92 \%$ lower ratio of small grains than the wire fabricated by the low-purity process. The grain size distribution in the trench depth direction for the Cu wire plated without additives was much more uniform than that plated with additives. [doi:10.2320/matertrans.M2012331]
\end{abstract}

(Received October 4, 2012; Accepted November 20, 2012; Published January 19, 2013)

Keywords: copper wire, nano-scale, additive-free plating, electron backscatter diffraction (EBSD), microstructure

\section{Introduction}

Copper has been extensively used as the interconnect material for advanced ultra-large scale integrations (ULSIs) due to its low electrical resistivity and high stability against electro-migration. ${ }^{1)}$ The underlying microstructure and texture of the copper wire significantly affect service properties of the ULSIs. ${ }^{2,3)}$ This is especially the case when wire width approaches the nano-scale range $(\leq 100 \mathrm{~nm})$ and electron scattering on grain boundaries, $\left.{ }^{4,5}\right)$ especially at very small grain boundaries in the lower region of a trench, ${ }^{6)}$ becomes an important factor. Therefore, in order to achieve low resistivity, it is necessary to reduce grain boundaries by a uniform grain coarsening process in the trench depth direction.

The grain growth in such narrow wire is believed to be substantially influenced by the trench geometry, as well as annealing conditions and impurity content. ${ }^{7-9)}$ According to Harper et al., ${ }^{10)}$ the impurities may preferentially concentrate at grain boundaries thus inhibiting grain growth. An obvious way to overcome this problem is minimization of impurity levels in plating material.

Previously, ${ }^{11)}$ it was shown that the wires fabricated by using high-purity $6 \mathrm{~N}^{12)}$-electrolyte and $9 \mathrm{~N}$-anode are characterized by a sufficiently lower resistivity than the wires manufactured by a conventional process $(3 \mathrm{~N}$-electrolyte and $4 \mathrm{~N}$-anode). It was also found that the effect of the electrolyte purity was much more pronounced than that of the purity of the anode. ${ }^{12)}$

An additional consideration arises from the fact that the additives used to enhance the filling capability in narrow trenches also introduce impurities into $\mathrm{Cu}$ wires. Hence, if the trench can be filled with $\mathrm{Cu}$ without additives, it would be expected to further enhance grain growth, especially in the lower region of the trench, and to reduce the resistivity by being able to use additive-free plating. Substantial resistivity reduction was confirmed using $100 \mathrm{~nm}$ wide $\mathrm{Cu}$ wires. ${ }^{13)}$ However, microstructures, i.e., grain size distributions and textures as a function of trench depth in the $\mathrm{Cu}$ wires less than $100 \mathrm{~nm}$ wide were not clarified in comparison with those of $\mathrm{Cu}$ wires formed by plating with additives.
The present work was focused on the characterization of microstructure and texture in the nano-scale $\mathrm{Cu}$ wire as a function of purity of plating material and trench depth. Attempting to provide a fundamental insight into the microstructure, high-resolution electron backscatter diffraction (EBSD) combined with a sophisticated chemical mechanical polishing (CMP) technique was used for microstructural and textural observations.

\section{Experimental Procedure}

The damascene trenches with $80 \mathrm{~nm}$ width and $200 \mathrm{~nm}$ height were patterned into $\mathrm{SiO}_{2} / \mathrm{Si}$ film by electron beam lithography and reactive ion etching. An ultra-thin TaN/Ta $(7.5 \mathrm{~nm} / 7.5 \mathrm{~nm})$ barrier layer and a $50 \mathrm{~nm}$ thick $\mathrm{Cu}$ seed layer were deposited onto the trenches. Figure 1(a) shows a schematic drawing of the trench structure. The reference directions used in this study were denoted as the normal direction (ND), transversal direction (TD) and longitudinal direction (LD).

$\mathrm{Cu}$ was deposited into the trenches by three types of electroplating processes.

(1) Low-purity process: DC electroplating process at a current density of $5 \mathrm{~mA} / \mathrm{cm}^{2}$ and conventional purity plating materials $\left(3 \mathrm{~N}-\mathrm{CuSO} \cdot 5 \mathrm{H}_{2} \mathrm{O}\right.$ electrolyte and $4 \mathrm{~N}$ $\mathrm{Cu}$ anode, abbreviated as $3 \mathrm{~N} / 4 \mathrm{~N}$ ) were used. Additives consisting of organic accelerator, organic suppressor and organic leveler were added to solution to enhance the filling capability.

(2) High-purity process: the same as process (1), but high purity plating materials $\left(6 \mathrm{~N}-\mathrm{CuSO}_{4} \cdot 5 \mathrm{H}_{2} \mathrm{O}\right.$ electrolyte and $8 \mathrm{~N}-\mathrm{Cu}$ anode, $6 \mathrm{~N} / 8 \mathrm{~N})$ were used.

(3) Additive-free process: pulse electroplating process and $6 \mathrm{~N} / 8 \mathrm{~N}$ plating materials were used, and without additives in the electrolyte. The pulse waves we used are shown in Fig. 1(b).

The electroplated $\mathrm{Cu}$ films were $300 \mathrm{~nm}$ thick. After deposition, specimens were immediately annealed at $573 \mathrm{~K}$ for $10 \mathrm{~min}$ by the IR-RTA (infrared-rapid thermal annealing) method. The heating rate was $1.7 \mathrm{~K} / \mathrm{s}$. 


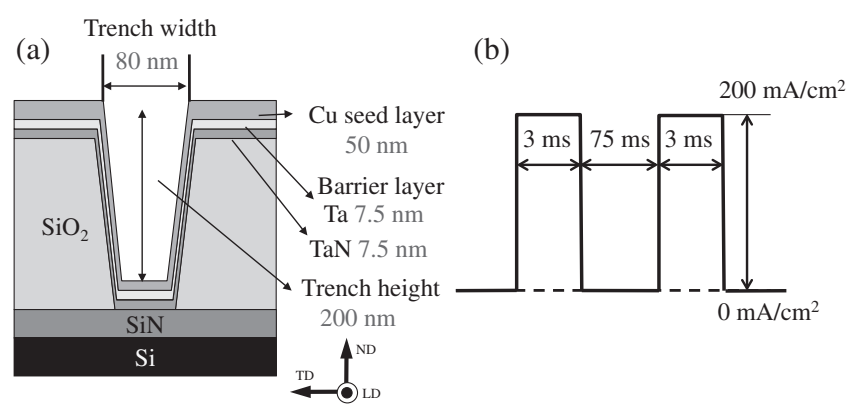

Fig. 1 (a) Schematic drawing of the trench structure for $\mathrm{Cu}$ electroplating. (b) pulse conditions for additive-free process.

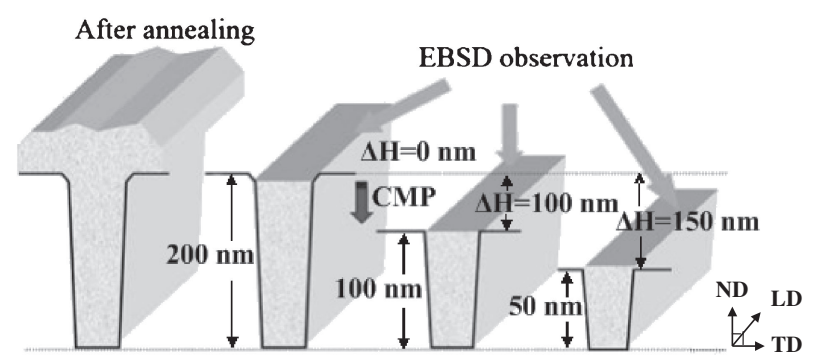

(3)

(4)

Fig. 2 Schematic drawing of specimens polished down to three selected heights: (2) $200 \mathrm{~nm}$, (3) $100 \mathrm{~nm}$ and (4) $50 \mathrm{~nm}$ using the CMP technique.
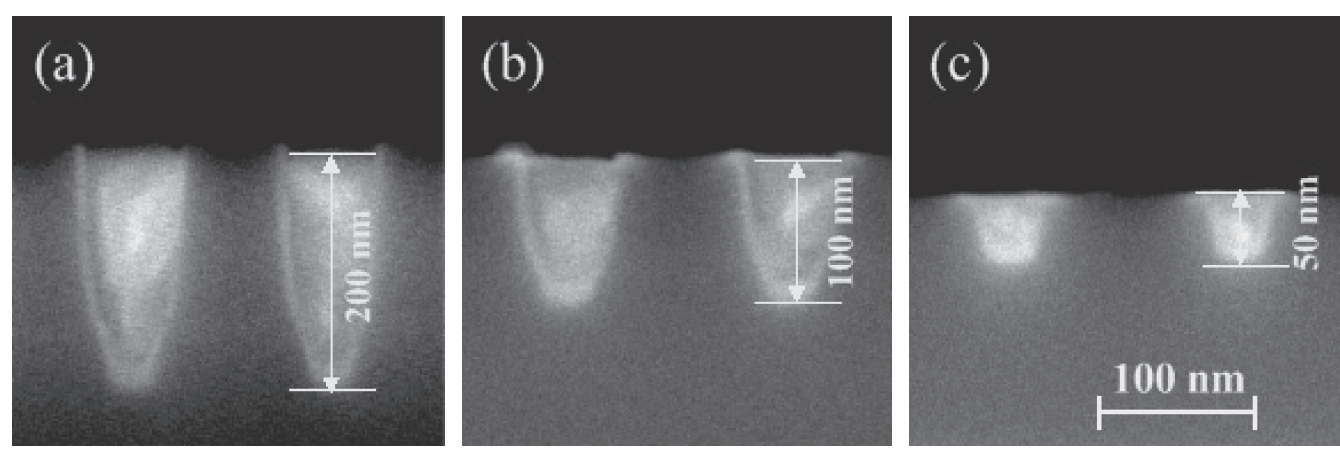

Fig. 3 Cross-sectional SEM images of $\mathrm{Cu}$ wire plated by additive-free process with trench heights of (a) $200 \mathrm{~nm}$, (b) $100 \mathrm{~nm}$ and (c) $50 \mathrm{~nm}$.

To investigate the microstructure distribution in the thickness direction of the lines, the annealed specimens were polished down to three selected heights $(200,100$ and $50 \mathrm{~nm})$ by using the CMP technique, as illustrated in Fig. 2. Figure 2(1) shows the $\mathrm{Cu}$ wire with the overburden layer on it. Figure 2(2) shows the $\mathrm{Cu}$ wire after removal of this overburden layer. Figure 2(3) and (4) respectively show $\mathrm{Cu}$ wires after removal of 100 and $150 \mathrm{~nm}$ depths by CMP. Hereafter, these are referred to as $\mathrm{Cu}$ wires with 200, 100 and $50 \mathrm{~nm}$ heights, respectively. Microstructural observations were done mainly by EBSD using the Hitachi S-4300SE field emission gun scanning electron microscope (FE-SEM) equipped with the TSL OIM ${ }^{\mathrm{TM}}$ EBSD system.

\section{Results and Discussion}

Figure 3 shows cross-sectional SEM images of $80 \mathrm{~nm}$ wide $\mathrm{Cu}$ wires after annealing and with the heights of 200 , 150 and $50 \mathrm{~nm}$ formed by CMP. It can be seen that the trenches were entirely filled with $\mathrm{Cu}$ by additive-free process.

Figure 4 illustrated the grain structure at three different heights of the $\mathrm{Cu}$ wires formed with low-purity, high-purity and additive-free processes. The EBSD maps were acquired with a scan step size of $30 \mathrm{~nm}$. To improve reliability of EBSD data, all the maps were preprocessed by an imagequality selection option and a standard grain-dilation option of the TSL software. The grain tolerance angle was set as $5^{\circ}$. These procedures eliminated the grains with low diffraction and small size (less than 3 pixels) from the EBSD data set. The final obtained EBSD maps shown in Fig. 4 contain the "copper wire" data only, and the inter-trench spaces appear as black due to their amorphous structures (low image-quality).
In these EBSD maps, individual grains are colored according to their crystallographic orientation relative to the ND; the color code triangle is shown in the bottom right corner.

In all cases, the grains typically span across the entire line width thus producing a bamboo-like structure. It is worth noting that the grains at the $50 \mathrm{~nm}$ height have smaller grain size and different preferential crystallographic orientation compared to the grains at 100 and $200 \mathrm{~nm}$ heights of $\mathrm{Cu}$ wire.

The grain size were calculated by TSL software from the EBSD maps using a method that assumed each grain to be a circle and the equivalent grain diameters were calculated (socalled grain reconstruction method). The grain size distribution was plotted as the lognormal distribution function: ${ }^{14)}$

$$
f(D, \mu, \sigma)=\frac{1}{\sqrt{2 \pi} D \ln \sigma} \exp \left(-\frac{(\ln D-\ln \mu)^{2}}{2(\ln \sigma)^{2}}\right)
$$

where $D$ is the grain size, $\mu$ is the median grain size value, and $\sigma$ is a parameter related to the scattering width. The results are shown in Fig. 5. Ratios of grains with diameters less than $45 \mathrm{~nm}$ are also shown. $45 \mathrm{~nm}$ is about the mean free path of $\mathrm{Cu}$, and these grains will significantly raise the $\mathrm{Cu}$ resistivity. The numbers of grains below $45 \mathrm{~nm}$ were counted by the TSL software, and then the ratios of these grains were calculated. These values correspond to the area fraction under the lognormal fitting curves with grain sizes less than $45 \mathrm{~nm}$.

It can be seen in Fig. 5 that with decreasing wire heights from 200 to $50 \mathrm{~nm}$, the median grain sizes decrease and the ratios of grains below $45 \mathrm{~nm}$ increase for all the processes, and with increasing purity of plating materials, the median grain sizes increase and the ratios of grains below $45 \mathrm{~nm}$ decrease. 


\section{low-purity}
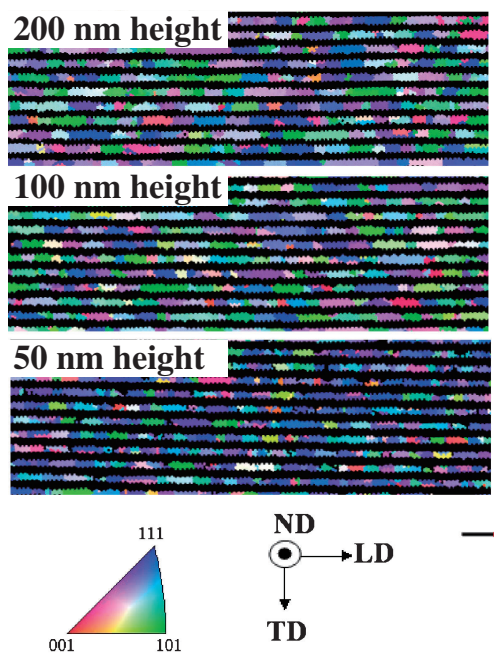

high-purity

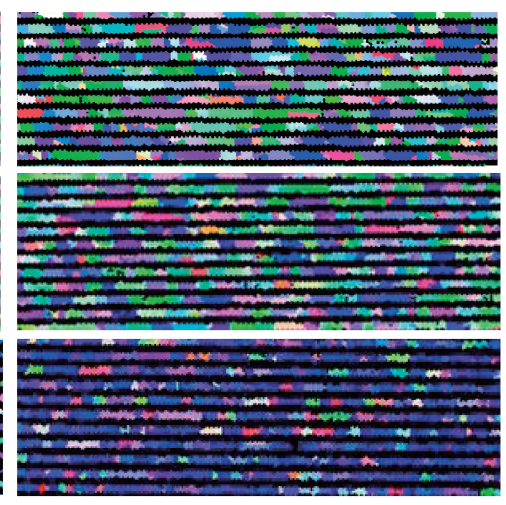

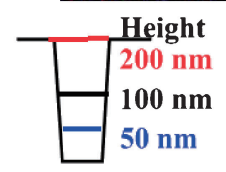

additive-free

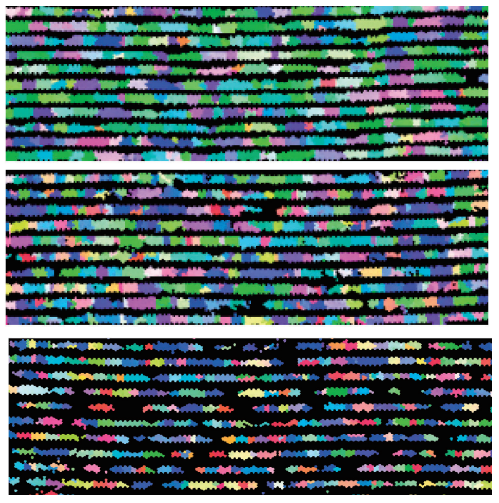

$2 \mu \mathrm{m}$

Fig. 4 Inverse pole figure (IPF) maps of $\mathrm{Cu}$ wires at different trench heights. $\mathrm{Cu}$ wires formed with the low-purity, high-purity and additive-free processes.
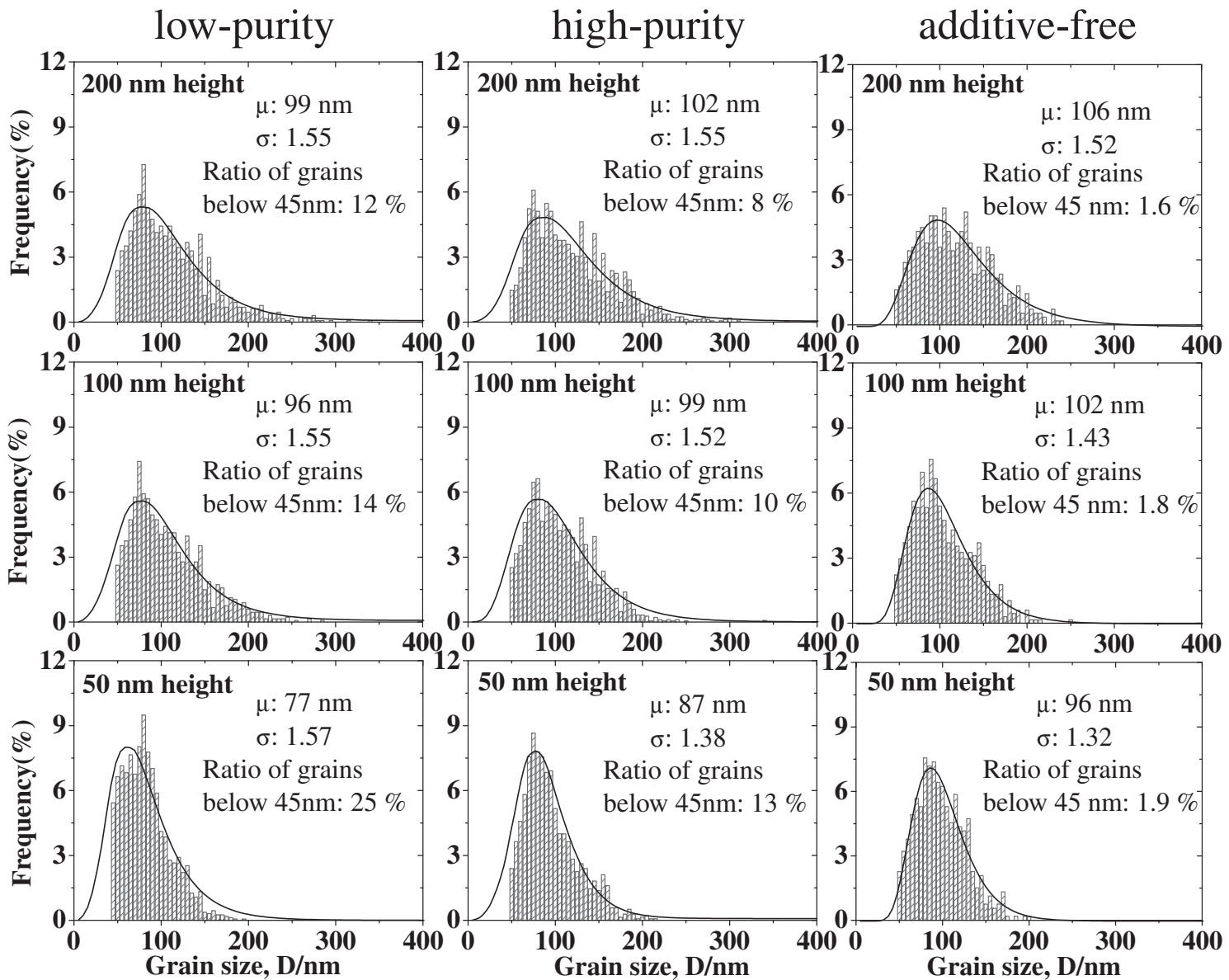

Fig. 5 Lognormal distribution of grain size at three selected heights of $\mathrm{Cu}$ wires fabricated by the low-purity, high-purity and additive-free processes. $\mu$ : median grain size; $\sigma$ : a parameter related to the scattering width.

The median grain sizes are summarized in Fig. 6. For all the processes, grain sizes at the $50 \mathrm{~nm}$ height are much smaller than those at the 200 and $100 \mathrm{~nm}$ heights. This indicates that the grain growth is relatively difficult at the lower height. One of the possible explanations for this phenomenon is the grain growth in the lower region is restricted by both the bottom and sidewalls, while in the higher region growth is restricted only by the side walls.

Comparing the grain sizes for these three processes, at both 200 and $100 \mathrm{~nm}$ heights, shows the grain sizes are broadly 


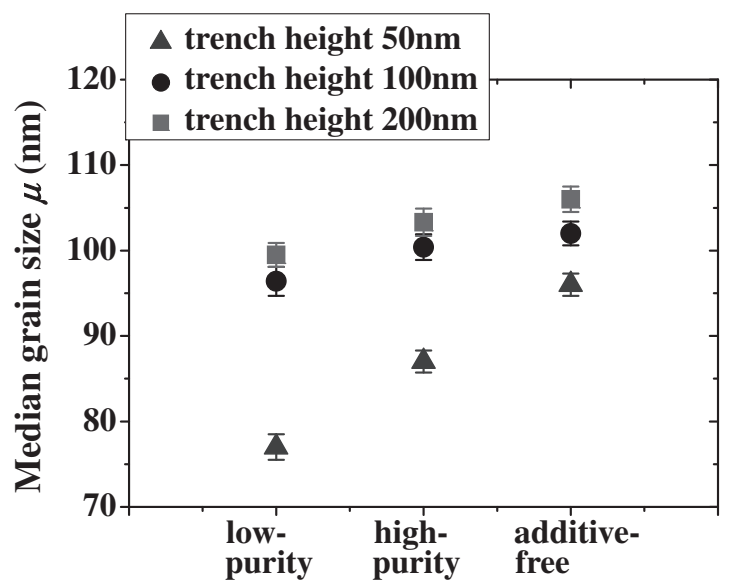

Fig. 6 The median grain size of $\mathrm{Cu}$ wires formed with low-purity, highpurity and additive-free processes.

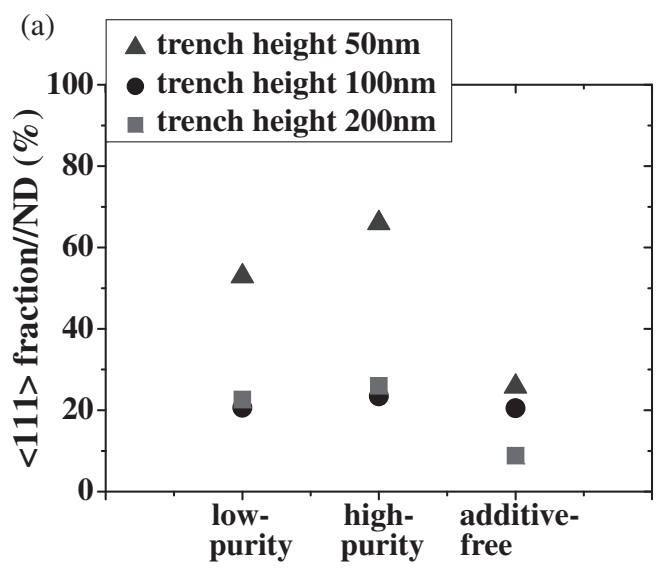

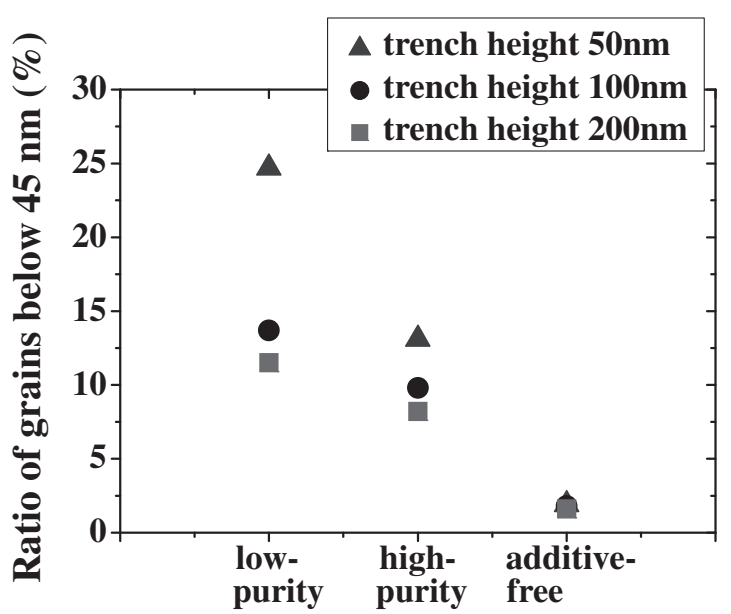

Fig. 7 The ratio of grains below $45 \mathrm{~nm}$ for $\mathrm{Cu}$ wires formed with lowpurity, high-purity and additive-free processes.

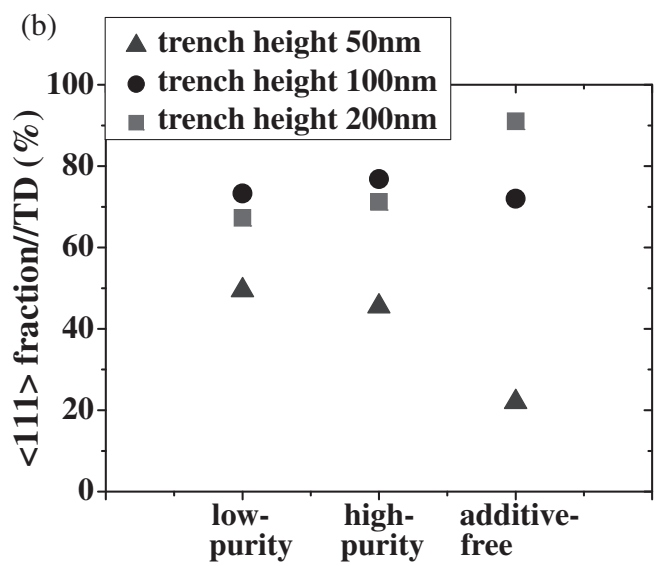

Fig. 8 The fraction of $\langle 111\rangle$ oriented grains (a) parallel to the normal direction and (b) parallel to the transverse direction of $\mathrm{Cu}$ wires formed with low-purity, high-purity and additive-free processes.

similar to each other. At the $50 \mathrm{~nm}$ height, however, for the $\mathrm{Cu}$ wire formed with the high-purity process, grain size is $13 \%$ larger than that for the $\mathrm{Cu}$ wire formed with the lowpurity process, and for the $\mathrm{Cu}$ wire formed with the additivefree process, it is $25 \%$ larger than that for the $\mathrm{Cu}$ wire formed with the low-purity process.

Furthermore, the ratios of small grains with diameters less than 45 are shown in Fig. 7. It is also clear that the decreasing trend of the ratio with increasing purity is much more remarkably seen at the $50 \mathrm{~nm}$ height than at 200 and $100 \mathrm{~nm}$ heights. The ratio of small grains for the $\mathrm{Cu}$ wire formed with the high-purity process is about $50 \%$ lower than that for the $\mathrm{Cu}$ wire formed with the low-purity process, and for the additive-free process, it is $92 \%$ lower than that for the lowpurity process. This result corresponds to the fact that resistivities of $\mathrm{Cu}$ wires formed by additive-free plating are substantially lower than those of $\mathrm{Cu}$ wires formed by plating with additives. ${ }^{13)}$ This effect may be explained as the high purity of plating materials reduces the segregation of impurities such as $\mathrm{O}, \mathrm{Cl}$ and $\mathrm{S}^{8,11,15,16)}$ at the grain boundaries and decreases the ratio of defects which would depress the grain growth and introduce random orientation. The present study, however, provides the new, important result that the effect of purity of plating materials on grain growth is more significant in the lower region of the trench than that in other regions. This means that the additive-free process results in much more uniform grain coarsening during annealing and contributes to a uniform grain size distribution in the depth direction of the trenches.

To illustrate the texture distribution within the $\mathrm{Cu}$ wires, the fraction of $\langle 111\rangle$ oriented grains derived from EBSD maps were arranged as parallel to the ND and TD and are summarized in Fig. 8. For both the processes with additives in the electrolyte (low-purity process and high-purity process), the grains at the $50 \mathrm{~nm}$ height of $\mathrm{Cu}$ wire are oriented such that $\langle 111\rangle$ direction is nearly parallel to the ND; this indicates that the $\{111\}$ plane tends to align with the bottom surface. On the other hand, the grains at 200 and $100 \mathrm{~nm}$ height of $\mathrm{Cu}$ wire are oriented such that the $\langle 111\rangle$ direction is nearly parallel to the TD; this indicates the alignment of the $\{111\}$ planes with the trench sidewalls. These observations indicate that at the $50 \mathrm{~nm}$ height, the bottom up $\mathrm{Cu}$ growth is more dominant than growth from the sidewalls; however, at 200 and $100 \mathrm{~nm}$ heights, $\mathrm{Cu}$ grain growth from the sidewalls is more dominant than growth from the bottom of the trench. Based on the above results, a schematic drawing is given in Fig. 9(a). In this figure, the thickness of the arrows corresponds to the trend of crystal 
(a)

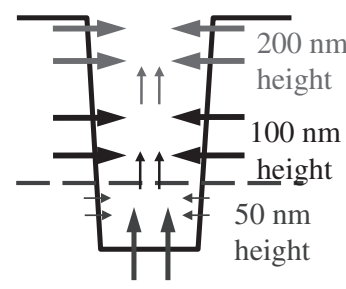

(b) Without additives

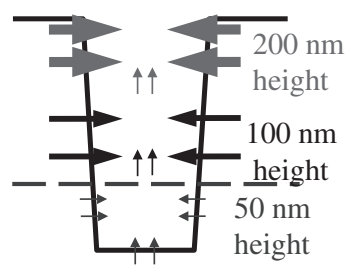

Fig. 9 Schematic drawing of the grain growth direction at three selected heights of $\mathrm{Cu}$ wires plated (a) with and (b) without additives.

growth, i.e., the thicker the arrow, the easier to crystal growth. It may be concluded that the grain nucleation mechanism alters with the trench depth.

The texture distributions are broadly similar in $\mathrm{Cu}$ wires plated with the two processes having additives in the electrolyte; however the distribution in $\mathrm{Cu}$ wires plated without additives differs from them. At 200 and $100 \mathrm{~nm}$ heights, the grains orient as the $\langle 111\rangle$ direction parallel to the TD, which is the same as in the wires obtained by the processes with additives; however, the fraction of $\langle 111\rangle$ oriented grains for the additive-free process is much higher than the fractions for the other two processes, especially at the $200 \mathrm{~nm}$ height, more than $90 \%$ of the grains are oriented as $\langle 111\rangle / / \mathrm{TD}$. On the other hand, at the $50 \mathrm{~nm}$ height, the fractions of $\langle 111\rangle$ oriented grains both parallel to ND and parallel to TD are very low. This indicates that for the additive-free process the orientation is random at the $50 \mathrm{~nm}$ height of $\mathrm{Cu}$ wire. This effect may be explained in terms of grain coarsening in the lower region of the trench. This is illustrated in the schematic drawing of Fig. 9(b).

Therefore, the observed results that the $\{111\}$ plane is aligned with a substrate surface (either the sidewalls or bottom plane) and that there is random orientation in the lower region for the $\mathrm{Cu}$ wire plated without additives are most likely associated with minimization of interface energy.

\section{Conclusions}

In this work, the EBSD technique was employed to study the effect of plating material purity on microstructure of the nano-scale $\mathrm{Cu}$ wires. The grain size distribution and texture distribution of $\mathrm{Cu}$ wires formed with low-purity, high-purity and additive-free processes were investigated as a function of trench depth. The influence of plating material purity on microstructures was found to be remarkable at the $50 \mathrm{~nm}$ height of $\mathrm{Cu}$ wire. After annealing, the $\mathrm{Cu}$ wire fabricated by the additive-free process had $13 \%$ larger grains and $80 \%$ lower ratio of small grains (less than $45 \mathrm{~nm}$ ) than wire fabricated by the high-purity process, and $25 \%$ larger grains and $92 \%$ lower ratio of small grains than wire fabricated by the low-purity process. The grain size distribution in the trench depth direction for the $\mathrm{Cu}$ wire plated without additives was much more uniform than that plated with additives. However, $\langle 111\rangle$ orientation in the lower region of the trench of the $\mathrm{Cu}$ wire formed with the additive-free process was found to be more random compared to that plated with additives.

\section{Acknowledgements}

The financial support by Grants-in-Aid for Science Research under Contract Nos. 17206071 and 20226014 and by JST is greatly appreciated. The authors also would like to thank Nippon Mining \& Metal Co., Ltd. for supplying the high purity $\mathrm{CuSO}_{4} \cdot 5 \mathrm{H}_{2} \mathrm{O}$ and the ultrahigh purity anode $\mathrm{Cu}$ plate. They also acknowledge Prof. Yasushi Sasajima and Dr. Suguru Tashiro for valuable discussions.

\section{REFERENCES}

1) D. Edelstein, et al.: Electron Devices Meeting, 1997, IEDM'97, Technical Digest, International, (1997) p. 773.

2) W. Steinhogl, G. Schindler, G. Steinlesberger and M. Engelhardt: Phys. Rev. B 66 (2002) 075414-075417.

3) K. Hinode, Y. Hanaoka, K. Takeda and S. Kondo: Jpn. J. Appl. Phys. 40 (2001) L1097-L1099.

4) W. Wu, S. H. Brongersma, M. Van Hove and K. Maex: Appl. Phys. Lett. 84 (2004) 2838-2840.

5) W. Steinhogl, G. Schindler, G. Steinlesberger, M. Traving and M. Engelhardt: J. Appl. Phys. 97 (2005) 023706.

6) K. Khoo, J. Onuki, T. Nagano, Y. Chonan, H. Akahoshi, T. Tobita, M. Chiba, T. Saito and K. Ishikawa: Jpn. J. Appl. Phys. 45 (2006) L852L853.

7) W. Zhang, S. H. Brongersma, N. Heylen, G. Beyer, W. Vandervorst and K. Maex: J. Electrochem. Soc. 152 (2005) C832-C837.

8) M. Stangl, J. Acker, S. Oswald, M. Uhlemann, T. Gemming, S. Baunack and K. Wertzig: Microelectron. Eng. 85 (2008) 534.

9) J. Neuner, I. Zienert, A. Peeva, A. Preuße, P. Kücher and J. W. Bartha: Microelectron. Eng. 87 (2010) 254-257.

10) J. M. E. Harper, C. Cabral, Jr., P. C. Andricacos, L. Gignac, I. C. Noyan, K. P. Rodbell and C. K. Hu: J. Appl. Phys. 86 (1999) 25162525 .

11) J. Onuki, S. Tashiro, K. P. Koo, N. Ishikawa, T. Kimura, Y. Chonan and H. Akahoshi: J. Electrochem. Soc. 157 (2010) H857.

12) S. Tashiro, K. P. Khoo and J. Onuki: J. Japan Inst. Metals 75 (2011) 223-228.

13) J. Onuki, K. Tamahashi, T. Namekawa and Y. Sasajima: Mater. Trans. 52 (2011) 1818-1823.

14) H. Natter and R. Hempelmann: J. Phys. Chem. 100 (1996) 1952519532.

15) J. H. Sukamoto and J. D. Reid: Electrochem. Soc. Proc., Impact of bath composition on the purity and room temperature anneal characteristics of thin copper film, (2004) p. 96.

16) S. H. Brongersma, E. Kerr, I. Vervoort, A. Saerens and K. Maex: J. Mater. Res. 17 (2002) 582-589. 